\title{
...UND TÄGLICH GRÜSST DAS MURMELTIER...
}

\section{Liebe Kolleginnen und Kollegen,}

irgendwie kommt mir vor, ich schreibe dauernd Vorwörter für unsere Zeitschrift und es ändert sich an den äußeren Umständen, unter denen wir arbeiten, leben und uns fortbilden, nichts.

Demensprechend kann ich berichten, dass wir unseren TAO-Kongress wieder als den einzigen internationalen Kongress in Europa live abgehalten haben. Darauf bin ich unglaublich stolz! Mittlerweile haben wir ja schon gut Übung darin und alles hat wunderbar geklappt. Einige Referenten, besonders die Amerikaner, mussten als LIVESchaltung auf großen Leinwänden im Seminarraum gestreamt werden, was aber der Qualität derVorträge keinen Abbruch tat. Im Gegenteil, dieses LIVE-Streaming im Kinoformat werden wir teilweise beibehalten bei internationalen Referenten aus anderen Kontinenten.

Unsere Ausbildungen gingen im Herbst als Präsenzveranstaltungen los und werden nun aufgrund derVerordnungen und Situation teilweise wieder als Webinare abgehalten oder aber auch alsVideo-Aufzeichnung angeboten. Wir sind ja für alle Möglichkeiten gerüstet.
Auch heuer bieten wir wieder unser virtuelles Charity-Event an: den OGKA-Adventkranz, wo jeden Adventsonntag ein Vortrag eines OGKA-Referenten bzw. einer OGKA-Referentin inklusive einer persönlichen adventlichen Darbietung online erhältlich ist. Ein Teil der Einnahmen geht als Spende an die Roten Nasen Clowndoctors, deren wunderbare Arbeit in diesen Zeiten noch wichtiger wird.Vielleicht mögen Sie mit uns durch den Advent spazieren. Infos sind auf unserer Homepage zu finden.

In diesem Sinne wünsch ich Ihnen eine wunderbare Vorweihnachts und Weihnachtszeit!

Wir lesen uns im neuen Jahr!

Möglicherweise wird das ja besser ... aber hab ich das nicht schon die letzten Male geschrieben? ....

Ihre

O. Pojer

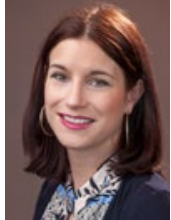

Dr. med. univ. Olivia Pojer

Präsidentin der Österreichischen Gesellschaft für kontrollierte Akupunktur und TCM (OGKA)

Glacisstraße 7, A-8010 Graz

Tel. $+43316 / 374050$

E-Mail:office@ogka.at, Internet:www.ogka.at 